\title{
Antihypertensive Prescription Pattern and Associated Medication Costs: A Retrospective Review of Prescriptions in A Tertiary Hospital
}

\section{Onah Otor Paul'*, Aliyu Kaigama², Ahmed Abdulmalik ${ }^{3}$}

\author{
${ }^{1}$ Department of clinical pharmacy and pharmacy administration, Faculty of Pharmacy University of Maiduguri, \\ Borno State, Nigeria \\ 2Department of clinical pharmacy and pharmacy administration, Faculty of Pharmacy University of Maiduguri, \\ Borno State, Nigeria \\ 3Department of clinical pharmacy and pharmacy administration, Faculty of Pharmacy University of Maiduguri, \\ Borno State, Nigeria
}

\begin{abstract}
A B S T R A C T
Background: Hypertension is the leading cardiovascular disease most associated with high risk of morbidity and mortality. Recent evidence indicate that in low and medium income countries hypertension is a growing healthcare challenge compounding already existing high burden of infectious diseases. The overall goal of treatment is to reduce the risk of associated secondary complications which increases the risk of mortality. The choice of antihypertensive medications vary widely between and within health facilities, however concerns remain whether prescribed drugs affordable as well as optimize treatment outcomes.

Aim: The aim of this study is to determine antihypertensive prescription pattern and its impact on affordability of drug treatment Results/Discussions: The results showed that monotherapy with CCBs were the most prescribed drugs accounting for over half of all antihypertensive prescriptions. In addition $\mathrm{CCB}$ based combination therapies were found in more than three quarters of all prescriptions. The cost of one month supply of innovator brands was significantly higher than generic versions, which made them far less affordable to majority of patients. The prescription pattern did not significantly adhere to current treatment guidelines for the management of hypertension. This makes the case for improvement in prescription practices that emphasize rational drug therapy that take into cognizance costs, particularly among the poor.

Conclusion: Antihypertensive prescription pattern did not largely comply with guidelines and the widespread prescription of innovator drug brands makes medicines largely unaffordable to majority of patients. It is imperative that drug treatment of high blood pressure allow patients to benefit from reduced cost of low priced generic drugs.
\end{abstract}

Keywords- Hypertension, cardiovascular disease, Antihypertensive, antihypertensive prescription, morbidity

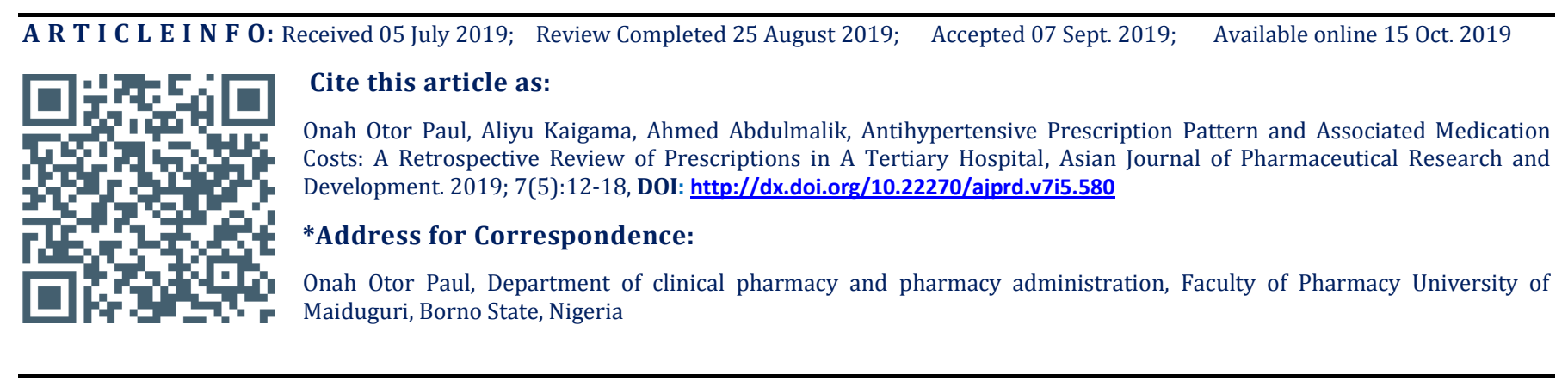

\section{INTRODUCTION}

$\mathrm{H}$ ypertension is among the most common noncommunicable disease of global public health concern. It is associated with increased rate of morbidity and mortality, its a major risk factor for chronic kidney disease, stroke and cardiovascular disease ${ }^{1,2}$ Recent estimates showed that over a billion people are affected and projections indicate that it's likely to rise to 1.5 billion by $2025^{3}$. Epidemiological studies suggest that developing and low income countries have a greater burden of the disease, unfortunately healthcare systems are weak and access to effective treatment is limited. In Nigeria, hypertension 
prevalence is reported to be between $12-36.6 \%{ }^{4,5,6,7}$. Prevalence vary widely with age, previous studies showed that those $\geq 65$ have greater prevalence ${ }^{8,9}$ and prevalence in urban areas was reported to be higher than among rural dwellers ${ }^{10}$.Among the many factors adduced for the increasing prevalence of hypertension are ageing, excessive alcohol use, sedentary lifestyle, obesity, stress and environmental factors. Globally hypertension is estimated to cause 9.4 million deaths annually, half of mortality due to stroke and heart diseases is caused by hypertension ${ }^{11,12}$. Clinical evidence clearly indicates that antihypertensive therapy significantly reduces overall risk of heart failure, myocardial infarct, stroke, cardiac revascularization and chronic kidney disease among hypertensive patients ${ }^{13}$.

Several guidelines for treatment of hypertension exist and are being constantly updated, so it is therefore expected that clinicians will adopt the recommendations in the management of hypertensive disorder. However evidence from several studies suggest poor adherence to treatment guidelines 14,15,16,17,18,19.Approach to the treatment of hypertension varies widely, however it is imperative that $\operatorname{drug}(\mathrm{s})$ selection should be based on rational principles ${ }^{20}$. Rational prescribing is reported to have positive impact on clinical improvement and adherence to antihypertensive therapy ${ }^{21}$.

Treatment guidelines are generally intended to guide clinicians in selection of medication(s) that is appropriate for individual patients with due consideration to patient specific peculiarities. A number of studies reported that majority of patients do not achieve blood pressure target with monotherapies $22,23,24$. Majority of patients therefore had to be placed on multiple drug regimens to achieve blood pressure control $18,25,26,27,28,29,30$. A number of factors have been identified as having influence on antihypertensive drug prescription pattern and they include, age, comorbidities, adverse drug reactions, pregnancy, availability and cost of medications etc. So prescription pattern is a reflection of the influence of these and other factors on use of either monotherapy or multidrug therapies ${ }^{31,32,33,34,35}$.In low income countries like Nigeria where patients pay out of pocket for medications and healthcare services, cost can be a significant barrier to financial access, availability and affordability to medications for hypertension. So adhering to treatment guidelines have been shown to improve cost effective drug therapy resulting in significant savings for patients $36,37,38,39$. Prices of antihypertensives vary widely between drugs classes, brands, healthcare facility and market forces $40,41,42$.

The level of adherence to treatment guidelines vary widely as the diversity of study settings $43,44,45,46,47$. The most frequently used antihypertensives were diuretics, $\mathrm{CCBs}$, $\mathrm{BBs}, \mathrm{ACEI} / \mathrm{ARBs}$ and their various combinations ${ }^{48}$. It is important that antihypertensive prescriptions should take cost effectiveness into consideration because treatment is chronic in nature ${ }^{49}$.

\section{METHODS}

Setting: The study was carried out using prescription records of National health insurance scheme (NHIS) enrollees in the University of Maiduguri teaching hospital
Study design: This was a cross sectional descriptive retrospective study

Data collection: Prescription records between January 2017 and September 2018 of patients on NHIS at pharmacy department were used for the study. A total of 1602 prescriptions containing antihypertensive medications that met inclusion criteria were randomly selected. Exclusion criteria include incomplete prescriptions, NHIS numbers not indicated on prescription and those written on unofficial prescription forms. Data extracted from prescriptions included name(s) of drugs, demographic data, antihypertensive drugs, dosage, frequency of dosing and brand.

Data analysis: The data was entered into SPSS 21 for descriptive and inferential analysis. Student's test was used to find if differences in cost and affordability between innovator and generic brands of antihypertensive drugs and combination therapies. $\mathrm{P}$ values $\leq 0.05$ was considered statistically significant.

Objectives: To determine antihypertensive drugs prescription pattern and their affordability

Ethical approval: The study received ethical approval from the human research ethics committee of the University of Maiduguri teaching hospital, Borno State, Nigeria

\section{RESULTS}

\section{Demographic data}

The average age of patients was 57.6 years and females accounted for more than two thirds of the population [Figure $1 \& 2]$.

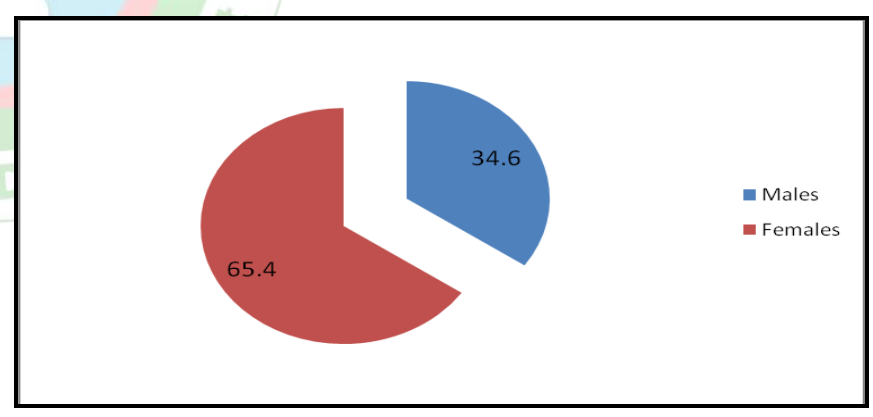

Figure 1: Gender distribution

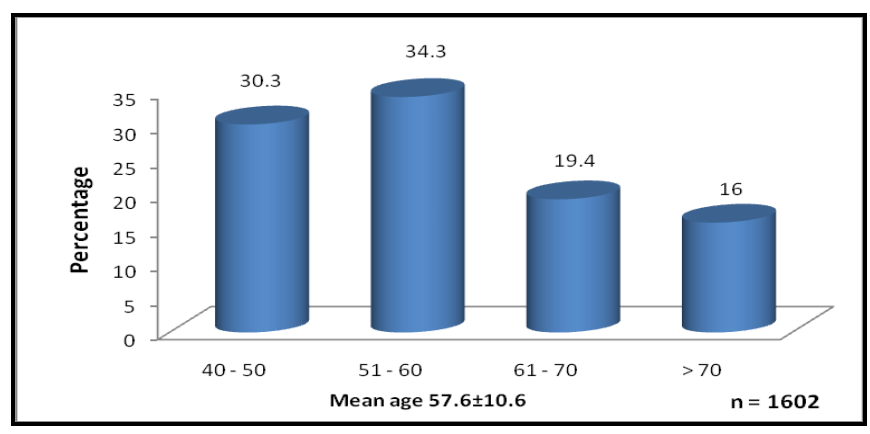

Figure 2: Age distribution

Antihypertensive monotherapies accounted for over two thirds of all prescriptions. Calcium channel blockers were prescribed for over half of all patients on monotherapies. The average price for one month supply of innovator brands was 
2 - 15 times more expensive compared to that of their generic versions $[\mathrm{P}<0.05]$. Diuretics prescription rate was less than ten percent, while ACEI/ARBs and B blockers accounted for $23 \%$ and $5 \%$ of prescriptions respectively [Table 1].

Table 1: Comparison of median price ratios between monotherapies $[\mathrm{n}=1170]$

\begin{tabular}{|c|c|c|c|c|}
\hline Drugs & Number [\%] & IB [\$] & LPG [\$] & P- value \\
\hline Amlodipine & $560[47.9]$ & 17.1 & 1.1 & $<0.001$ \\
\hline Nifedipine & $103[8.8]$ & 2.1 & 0.8 & $<0.001$ \\
\hline Losartan & $73[6.2]$ & 3.0 & 1.4 & $<0.001$ \\
\hline Lisinopril & $182[15.6]$ & 2.1 & 0.9 & $<0.001$ \\
\hline Captopril & $15[1.3]$ & 2.7 & 1.1 & $<0.001$ \\
\hline Carvedilol & $32[2.7]$ & 1.9 & 1.4 & $<0.118$ \\
\hline Atenolol & $27[2.3]$ & 1.7 & 0.9 & $<0.001$ \\
\hline Bendrofluthiazide & $107[9.1]$ & 1.4 & 0.8 & $<0.001$ \\
\hline Methyldopa & $66[5.7]$ & 3.8 & 2.4 & $<0.001$ \\
\hline
\end{tabular}

Calculation was based on exchange rate of N315 to 1 USD and one month supply of medicine

Combination therapies based on CCBs were the most prescribed; they accounted for about $78.8 \%$ of all dual therapies. The combination of diuretics with CCBs, B blockers and ACEIs together accounted for less than a quarter of dual combination therapies. The cost of innovator brands in dual therapies were $2-9$ times more expensive compared to their generic counterparts $[\mathrm{P}<0.001$ [Table 2].

Table 2: Comparison of median price ratios of dual therapies $[n=338]$

\begin{tabular}{|l|c|c|c|c|}
\hline \multicolumn{1}{|c|}{ Drug combination } & Number [\%] & IB [\$] & LPG [\$] & P- value \\
\hline Amlodipine + Atenolol & $21[6.2]$ & 18.9 & 2.1 & $<0.001$ \\
\hline Amlodipine + Losartan & $45[13.3]$ & 20.2 & 2.5 & $<0.001$ \\
\hline Amlodipine + Lisinopril & $145[42.9]$ & 19.2 & 2.1 & $<0.001$ \\
\hline Amlodipine + Captopril & $36[10.6]$ & 19.8 & 2.2 & $<0.001$ \\
\hline Amlodipine + Bendrofluthiazide & $3[0.9]$ & 18.6 & 1.9 & $<0.001$ \\
\hline Nifedipine + Losartan & $7[2.1]$ & 5.1 & 2.2 & $<0.118$ \\
\hline Nifedipine + Lisinopril & $6[1.8]$ & 3.0 & 1.7 & $<0.001$ \\
\hline Nifedipine + Atenolol & $6[1.8]$ & 3.8 & 1.7 & $<0.001$ \\
\hline Nifedipine + Bendrofluthiazide & $3[0.9]$ & 3.5 & 1.7 & $<0.001$ \\
\hline Lisinopril + Bendrofluthiazide & $17[5.0]$ & 3.5 & 1.7 & 0.001 \\
\hline Lisinopril + Carvedilol & $5[1.5]$ & 3.9 & 2.4 & 0.202 \\
\hline Losartan + Atenolol & $3[0.9]$ & 4.8 & 2.4 & 0.131 \\
\hline Atenolol + Bendrofluthiazide & $11[3.3]$ & 3.2 & 1.7 & 0.208 \\
\hline Methyldopa + Bendrofluthiazide & $7[2.1]$ & 2.7 & 1.7 & 0.044 \\
\hline Methyldopa + Lisinopril & {$[0.6]$} & 5.2 & 3.3 & 0.044 \\
\hline Calation was based on exchange rate of N315 to 1 USD and one month supply of medicine & & \\
\hline
\end{tabular}

Among triple combination therapies, $\mathrm{CCBs}$ in combination with ACEI/ARBs were found in about $79 \%$ of all triple combination therapies. In addition $\mathrm{B}$ blockers were coprescribed in about $69 \%$ of patients [Table 3] 
Table 3: Comparison of median price ratios of triple combination therapies [ $n=94]$

\begin{tabular}{|l|c|c|c|c|}
\hline \multicolumn{1}{|c|}{ Drug combination } & Number [\%] & IB [\$] & LPG [\$] & P- value \\
\hline Amlodipine + Atenolol + Bendrofluthiazide & $560[47.9]$ & 17.1 & 1.1 & $<0.001$ \\
\hline Amlodipine + Atenolol + Lisinopril & $103[8.8]$ & 2.1 & 0.8 & $<0.001$ \\
\hline Amlodipine + Lisinopril + Carvedilol & $73[6.2]$ & 3.0 & 1.4 & $<0.001$ \\
\hline Amlodipine + Atenolol + Losartan & $182[15.6]$ & 2.1 & 0.9 & $<0.001$ \\
\hline Amlodipine + Losartan + Bendrofluthiazide & $15[1.3]$ & 2.7 & 1.1 & $<0.001$ \\
\hline Lisinopril + Atenolol + Bendrofluthiazide & $32[2.7]$ & 1.9 & 1.4 & $<0.118$ \\
\hline Nifedipine + Atenolol + Lisinopril & $27[2.3]$ & 1.7 & 0.9 & $<0.001$ \\
\hline Methyldopa + Atenolol + Losartan & $107[9.1]$ & 1.4 & 0.8 & $<0.001$ \\
\hline
\end{tabular}

\section{Calculation is based on N315 to 1 USD and 1 month supply of medicine}

Antihypertensive drugs prescribed as innovator brands are generally $2-15$ times more expensive compared to generic versions. Affordability is generally lower for innovator brands and they become progressively less affordable as combination of drugs increased. It would take $2-11$ days of daily wages to afford one month supply of antihypertensive drugs prescribed in branded form compared to generics which were generally affordable.

Table 4: Comparison of affordability between innovator and generic versions

\begin{tabular}{|c|c|c|}
\hline Drugs/ combination & IB [Days] & LPG [Days] \\
\hline Amlodipine & 9.0 & 0.6 \\
\hline Nifedipine & 1.1 & 0.4 \\
\hline Losartan & 1.6 & 0.7 \\
\hline Lisinopril & 1.2 & 0.5 \\
\hline Captopril & 1.4 & 0.6 \\
\hline Carvedilol & 1.0 & 0.7 \\
\hline Atenolol & 0.9 & 0.5 \\
\hline Bendrofluthiazide & 0.7 & 0.4 \\
\hline Methyldopa & 2.0 & 1.3 \\
\hline Dual therapies $[n=338]$ & IB [Days] & LPG [Days] \\
\hline Amlodipine + Atenolol & 9.9 & 1.1 \\
\hline Amlodipine + Losartan & 10.6 & 1.3 \\
\hline Amlodipine + Lisinopril & 10.1 & 1.1 \\
\hline Amlodipine + Captopril & 10.4 & 1.2 \\
\hline Amlodipine + Bendrofluthiazide & 9.8 & 1.0 \\
\hline Nifedipine + Losartan & 2.7 & 1.1 \\
\hline Nifedipine + Lisinopril & 1.6 & 0.9 \\
\hline Nifedipine + Atenolol & 2.0 & 0.9 \\
\hline Nifedipine + Bendrofluthiazide & 1.8 & 0.9 \\
\hline Lisinopril + Bendrofluthiazide & 1.8 & 0.8 \\
\hline Lisinopril + Carvedilol & 2.1 & 1.3 \\
\hline Losartan + Atenolol & 2.5 & 1.3 \\
\hline Atenolol + Bendrofluthiazide & 1.7 & 0.9 \\
\hline Methyldopa + Bendrofluthiazide & 1.4 & 0.8 \\
\hline
\end{tabular}




\begin{tabular}{|c|c|c|}
\hline Methyldopa + Lisinopril & 2.7 & 1.7 \\
\hline Triple combination therapies $[n=94]$ & IB [Days] & LPG [Days] \\
\hline Amlodipine + Atenolol + Bendrofluthiazide & 10.6 & 1.5 \\
\hline Amlodipine + Atenolol + Lisinopril & 11.0 & 1.6 \\
\hline Amlodipine + Lisinopril + Carvedilol & 10.9 & 1.8 \\
\hline Amlodipine + Atenolol + Losartan & 11.5 & 1.8 \\
\hline Amlodipine + Losartan + Bendrofluthiazide & 11.3 & 1.7 \\
\hline Lisinopril + Atenolol + Bendrofluthiazide & 2.7 & 1.4 \\
\hline Nifedipine + Atenolol + Lisinopril & 3.2 & 1.4 \\
\hline Methyldopa + Atenolol + Losartan & 4.5 & 2.5 \\
\hline
\end{tabular}

\section{DISCUSSION:}

Demographic information indicated that the mean age of patients was comparable to other studies where adults over 40 years of age were more frequently diagnosed with hypertension ${ }^{18,49}$. Ageing is a known risk factor for the development of hypertension, however there are conflicting conclusions as to gender based risk of the disease. While some studies reported higher diagnosis of hypertension in females as observed in this study ${ }^{50.51}$, others suggest there is no significant difference between males and females' ${ }^{52}$.Antihypertensive medications are critical to long term blood pressure control and prevention of secondary complications. The drugs and their various combinations are usually tailored to meet blood pressure control target of individual patients. Prescription pattern of blood pressure lowering medications varies widely in-spite of evidence based clinical guidelines. The results of this study showed that monotherapy with Calcium channel blockers were the most commonly prescribed antihypertensive medications. This is in contrast with many previous studies which reported that diuretics were the most prescribed class of antihypertensive medications $49,51,53,54$. Current treatment guidelines recommend diuretics as first line medication and other drugs may be added if there is inadequate clinical response, however this appears not to be practice as shown in the results of this study.

The result also showed that Amlodipine was the most prescribed in contrast to several previous studies ${ }^{55,56,57}$, though other studies reported similar results to that of this study $42,45,50,58,59,60$. The prescription rate of ACEI/ARBs and other classes of antihypertensive medications have been

widely reported in literature ${ }^{61,62.63,64,65}$ with varying levels of prescription prevalence. Antihypertensive drug prescription practices in this study were not in tandem with the current treatment guidelines. While combination therapies are indicated in the presence of complications and/orcomorbidities, drug combinations observed in this

\section{REFERENCES}

1. Go AS, Mozaffarian D, Roger VL, American Heart Association statistics committee and Strokes statistics subcommittee et al. Heart disease and Stroke statistics - 2014 update. A report from the American Heart Association. Circulation 2013; 129: e28 - 292. study are not reflective of the principle of incremental addition until blood pressure control target is achieved ${ }^{66,67}$ The age of patients in this study suggest that many will benefit from diuretic based combination therapies while the elderly may be given CCBs as first line monotherapy. The prescription of CCBs, ACEI/ARBs and B blockers as first line monotherapies have little evidence supporting their superiority over diuretics and diuretic based combination therapies in achieving blood pressure control and reduction of morbidity and mortality ${ }^{68}$.

The availability and cost of medications is a problem of global concern particularly in low and medium income countries. In Nigeria cost of treating hypertension is mostly borne entirely by patients and in many cases in amounts that may be regarded as catastrophic expenditure ${ }^{69}$. The results of this study showed that cost of treating hypertension with monotherapies range from $1.4-17.1$ USD and $0.8-2.4$ USD for innovator and low priced generic versions respectively. The cost rises significantly with combination therapies, so affordability tend to reduce with increasing prescription of combination therapies. A comparism of one month cost of antihypertensive medication and income of least paid public sector employees revealed that monotherapies cost about $6.8 \%$ of monthly salary, while dual and triple therapies accounted for 16.1 and $27.4 \%$ of monthly salary respectively. The result of this study is much higher than previously reported ${ }^{49.70}$. The low affordability of antihypertensive drugs observed in this study has been previously reported in literature ${ }^{71,72,73}$. High cost of medicines can be a significant hindrance to achieving blood pressure target, so the use of cheaper generic drugs should be emphasized.

CONCLUSION: There is need to emphasize adherence to current treatment guidelines and also prescribe generic brands to lower cost of treatment. Antihypertensive combination therapies should adopt step wise approach using the most current clinical evidence.

Conflict of interests: The authors declare no conflict of interest

2. Kearney PM, Whelton M, Reynolds K, Munter P, Whelton PK, He J. Global burden of hypertension: Analysis of worldwide data. Lancet 2005; 365(9455):217 - 223.

3. Lim SS, Vos T, Flaxman AD, Danaci G, Shibuya K, Adair-Rohani H et al. A comparative risk assessment of burden of disease and injury attributable to 67 risk factors and risk factor clusters in 21 regions 
1990 - 2010: a systematic review for the global burden of disease study 2010. Lancet 2012; 380(9859):2224 - 2260.

4. Oladapo OO, Falase AO, Salako L, Sodiq O, Shoyinka K, Adedapo K. A prevalence of cardiometabolic risk factors among a rural Yoruba South Western Nigerian population: a population based survey. Cardiovasc J Afr 2010; 21(1):26 - 31.

5. Ofuya $Z$. The incidence of hypertension among a select population of adults in the Niger Delta region of Nigeria, Southeastern Asian J Trop Med Public Health 2007; 38(5):947 - 949.

6. Adedoyin RA, Mbada CE, Balogun MO, Martins T, Adebayo RA, Akintomide A et al. Prevalence and pattern of hypertension in a semi urban community in Nigeria. Eur J CardiovascPrevRehabil 2008; 15(6):683- 687.

7. Oladipo BA. Current epidemiology of hypertension in Nigeria. Arch Ibadan Med 2001; 1(1): $4-8$.

8. Kochen TA. Hypertensive vascular disease. In : Fauci AS, Braunwal EB, Kasper DL, Hauser SL, Longo DL, Jameson JL editors. Harrisons principles of internal medicine. $17^{\text {th }}$ edition. New York. McGraw Hill Inc 2008; 1549 - 1562.

9. Altaf M, Rasheed A, Mujtaba A, Mohammed S. Drug utilization evaluation of antihypertensives in geriatric patients in a tertiary care hospital. Int J Pharm Sci 2014; 6(9):261 - 264.

10. Gupta R. Trends in hypertension epidemiology in India. J Human hypertens $2004 ; 18: 73-78$.

11. WHO 2008. World Health Organization. Causes of death 2005. http://www.who.int/global_burden_diseases_/cod_2008_sources_met hods.pdfAccessed 3/4/19

12. World Health Organization. Global status report on noncommunicable diseases 2010. Geneva. World Health Organization 2011.

13. James PA, Oparil S, Carter BL, Cushman WC, DenninsonHimmerlfarb $\mathrm{C}$ et al. Eight joint national committee [JNC8]. Evidence based guidelines for the management of high blood pressure in adults: reports from the panel members appointed to the eight joint national committee [JNC8] Supplemental content. JAMA 2014; 311(5):507 - 520 .

14. Kabir Z, Feely J, Bennett K. Primary care prescribing pattern in Ireland after the publication of large hypertension trials. $\mathrm{Br} \mathrm{J}$ ClinPharmacol 2007; 64:381 - 385 .

15. Busari OA, Olanrewaju TO, Desalu OO, Opadijo GO, Jimoh AK, Agboola SM, Busari OE et al. Impact of knowledge attitudes and practices on hypertension on compliance with antihypertensive drugs in a poor resource setting. TAF Prevent Med Bull 2010; 9(2):87 - 92.

16. Psaty BM, Manolio TA, Smith NL, Heckbert SR, GoldienerJS ,Burke GL et al. Time trends in high blood pressure control and use of antihypertensive medications in older adults: The cardiovascular Health study. Arch Int Med 2002; 162:2325 - 2332.

17. Primastesta P, Brookes M, Poulter NR. Improved hypertension management and control: result from the health survey for England 1998. Hypertens 2001; 3:827-832.

18. Olanrenwaju TO, Aderibigbe A, Busari OA, Sanya ED. Antihypertensive drug utilization and conformity to guidelines in a sub - Saharan African hypertensive population. Int $\mathrm{J}$ ClinPharmacolTher 2010; 48(1):68 - 75 .

19. Romday R, Gupta AK, Bhambani P. An assessment of antihypertensive drug prescription pattern and adherence to joint national committee -8 hypertension treatment guidelines among hypertensive patients attending a tertriary care teaching hospital. Int J Res Med Sci. 2016; 4(12): 5125 - 5133.

20. Musini VM, Nazer M, Bassett K, Wright JM. Blood pressure lowering efficacy of monotherapy with Thiazides diuretics for primary hypertension. Cochrane database Syst Rev 2014; 5: CD003824.

21. Shrank WH, Hoang T, Ettner SL, Glassman PA, Nair K, Delapp D, Dirstine J, Avorn J, Arsh SM. The implications of choice: prescribing generic or preferred pharmaceuticals improves medication adherence for chronic conditions. Arch Intern Med 2006; 166(3):332 - 337.

22. Al-Drabah E, Irshald Y, Yasein N, Zmeill S. Prescription pattern of antihypertensive drugs in family practice clinics at Jordan University Hospital. Med Sci 2013; 2(1):469 - 488.

23. Theodorou M, Stafylas P, Kourlaba G, kaitelidou D, Maniadakis N, Papademetriou V. Physicians perceptions and adherence to guidelines for the management of hypertension: a national multicenter, prospective study. Int J Hypertens 2012.

24. Oluseyi A, Enajite O, Ikponmwosa I. Prescription pattern of antihypertensives medications and blood pressure control among hypertensive outpatients at the University of Benin teaching hospital in Benin City, Nigeria. Malawi Med J. 2017; 29(2):113 - 117.

25. Neal B, MacMahons S, Chapman N. Effects of ACE inhibitors, Calcium antagonists and other blood pressure lowering drugs: Results of prospectively designed overviews of randomized trials. Blood pressure lowering treatment trialists collaboration. Lancet 2000; 356:1955-1964.

26. Lemogoum D, Seedat YK, Mabadeje AFB, Mendis S, Bovet P, Onwubere $\mathrm{B}$ et al. Recommendation for prevention, diagnosis and management of hypertension and cardiovascular risk factors in sub Saharan Africa. J Hypertens 2003; 21:1993 - 2000.

27. Cushman WC, Ford CE, Cutler JA, Margolis KL, Davis BR, Grim $\mathrm{RH}$ et al. Success and predictors of blood pressure control in diverse north American settings. The antihypertensive and lipid lowering treatment to prevent heart attack trial [ ALLHAT]. J ClinHypertens $2002 ; 4: 339-340$.

28. Tamuno I, Babashani M. Blood pressure control among hypertensive patients in a tertiary healthcare facility in Northern Nigeria. Res $\mathbf{J}$ Med Sci 2012; 6(1):26 - 32.

29. Sharma AK, Dahiya N, Kairi JK, Bharati SM. Prescription patterns of antihypertensive drugs in a tertiary care hospital in India. Int $\mathrm{J}$ Basic ClinPharmacol 2015; 4:55 - 59.

30. Janagan T, Kavitha R, Sridevi SA, Veerendra V. Prescription pattern of antihypertensive drugs used in hypertensive patients with associated type 2 diabetes mellitus in a tertiary care hospital. Int $\mathbf{J}$ Pharm Res Rev 2014; 3(1):1 - 5.

31. Kaur S, Gupta S, Kumar D, Lal M, Gilani Z. Prescribing pattern of antihypertensive drugs in a tertiary care hospital in Jammu- A descriptive study. JK - Practitioner 2012; 17(4):38 - 41.

32. Fadare JO, Agboola SM, Opeke OA, Alabi RA. Prescription pattern and prevalence of potentially inappropriate medications among elderly patients in a Nigerian rural tertiary hospital. TherClin Risk Manage 2013;9:115 - 120.

33. Okhuelegbe ES, Odili VU, Iwuagwu MA, Igodo JO. Prescription pattern of antihypertensives and drug utilization in a general hospital Minna, Niger State, Nigeria. Pak J Pharm 2012; 25 (1 and 2):37 - 41.

34. Hussain Z, Sana A, Mohammed S, Razzaq MA. Patterns of drug therapy among diabetic hypertensive patients with other complications. Int J Pharm PharmSci 2014; 6(6):270 - 277.

35. St. Peter WL, Sozio SM, Shafi T, Ephraim PL, Luly J, McDevmottA et al. Pattern in blood pressure medication use in United States incident dialysis patients over the first 6 months. BMC Nephrol 2013; 14:249.

36. Karve AV, Chatter KB. Cost analysis study of oral antihypertensive agents available in Indian markets. Int J Basic ClinPharmacol 2014; $3: 479-483$

37. Sipla R, Helin-Salmivaara A, Korhonen MJ, Ketola E. Change in antihypertensive drug prescribing after guideline implementation: A controlled before and after study. BMC Family Practice 2011; 12: 87.

38. Fischer MA, Avom J. Economic implication of evidence based prescribing for hypertension: Can better care cost less? JAMA 2004; 291(15): 1850 - 1856 .

39. Osibogun A, Okwor T. Antihypertensive prescribing and cost patterns in an outpatient department of a teaching hospital in Lagos State, Nigeria. Op Prev Med Prev Med 2014; 4:156 - 163. 
40. Rimoy GH, Justin-Tenu M, Nilay C. Prescribing patterns and cost of antihypertensive drugs in private hospitals in Dar es Salam, Tanzania. East Cent Afr J Pharm Sci 2008; 11:69 - 73.

41. Amira CO, Okubadejo NU. Antihypertensive pharmacotherapy in a developing economy, pattern, acquisition costs and conformity to international guidelines in a tertiary care setting. J Human Hypertens 2006; 20:894 - 897 .

42. Rachana PR, Anuradha HV, Shivamurthy MC. Antihypertensive prescribing patterns and cost analysis for primary hypertension. A retrospective study. J ClinDiagn Res 2014;8(9):19 - 22.

43. Abdulameer SA, Sahib MN, Aziz NA, Hassan Y, Abdul HA, Razzaq $A$ et al. Physician adherence to hypertension guidelines and drug acquisitions costs antihypertensive drugs at the cardiac clinic : A pilot study. Patient Preferance and Adherence 2012; 6:101 - 108 .

44. Ahmad N, Hassan Y, Tangiisuran B, Meng OL, Abdaziz N, Khan AH. Guideline adherence and hypertension control in an outpatient cardiology clinic in Malaysia. Trop J Pharm Res 2012; 7(2): 665 672.

45. Odili VU, Oghagbon EK, Ugwa NA, Ochei UM, Aghomo OE. Adherence to international guidelines in the management of hypertension in a tertiary hospital in Nigeria. Trop J Pharm Res 2008; 7(2):945 - 952.

46. Shipra J, Prerna U, Jaswant G, Kumar A, Pushpawati J, Vikas S et al. A systematic review of prescription pattern monitoring studies and their effectiveness in promoting rational use of medicines. PerspectClin Res 2015; 6:86 - 90.

47. Xavier D, Noby M, Pradeep J, Prem P. Pattern of drug use in hypertension in a tertiary hospital: a cross sectional study in the in patients ward. Indian J Pharmacol 2001; 33:456 - 457.

48. Gu Q, Burt VL, Dillon CF, Yoon S. Trend in antihypertensive medication use and blood pressure control among United States adults with hypertension. The national health and nutrition examination in survey 2001 to 2010. Circulation 2012; 126(17):2105 -2114 .

49. Bakare OQ, Akinyinka MR, Goodman O, Kuyinu YA, Adeniran A, Odusanya OO, Osibogun A. Antihypertensive use, prescription pattern and cost of medications in a teaching hospital in Lagos, Nigeria. Niger J ClinPract 2016; 19: 668 - 672.

50. Katibi IA, Olarinoye JK. Antihypertensive therapy among hypertensive patients as seen in the middle belt of Nigeria. Ann Afr Med 2004; 4: 177 - 180

51. Adejumo O, Okaka E, Iyawe I. Prescription pattern of antihypertensive medication and blood pressure control among hypertensive outpatients of the University of Benin teaching hospital in Benin City, Nigeria. Malawi Med J 2017; 29(2): 113 - 117.

52. Oga OS, Okpechi I, Chukwuonye II, Akinyemi JO, Onwubere BJC, Falase $\mathrm{AO}$ et al. Blood pressure prevalence of hypertension and hypertension related complications in Nigerian Africans. A review. World J Cardiol 2012; 4(12): 327 - 340.

53. Mishra R, Kesarwani P, Keshari SS. Prescription pattern of antihypertensive drugs in a tertiary care teaching hospital. Int $\mathrm{J}$ Med Sci Public Health 2017; 6(4):684 - 686.

54. Kuchake VG, Maheshwani OD, Surana SJ, Patil PH, Digboe PN. Prescription pattern of antihypertension drugs in uncomplicated hypertensive patients at a teaching hospital. Indian J Pharm Pract 2009; 2(2):74-80.

55. Olanrewaju TO, Aderibigbe A, Chijioke A, Sanya EO, Busari OA, Kolo PJ et al. Descriptive analysis of blood pressure control among treated hypertensive patients in a tertiary hospital in Nigeria. Afr $\mathrm{J}$ Med MedSci 2011; 40(3):207 - 212.

56. Busari OA, Oluyombo R, Fasae AJ, Gabriel EO, Ayodele LM, Agboola SM et al. Prescribing pattern and utilization of antihypertensive drugs and blood pressure control in adults patients with systemic hypertension in a rural tertiary hospital in Nigeria. Am J Intern Med 2014; 2(6):144 - 149.

57. Ekwunike OI, Ubaka CM. Drug utilization, antihypertensive therapy among patients with compelling indications in two hospitals in south eastern Nigeria. J Pharm pharmacol Res 2011; 2: 25 - 28.

58. Etuk E, IsezuoSA, Chika A, Akuche J, Ali M. Prescription patterns of antihypertensive drugs in a tertiary health institution in Nigeria. Ann Afr Med 2009; 7:128 - 132.

59. Yusuff $\mathrm{KB}$, Balogun O. Physicians prescribing pattern of antihypertensive combinations in tertiary care setting in South Western Nigeria. J Pharm Sci 2005; 4(8):235 - 342.

60. Salako BL. Blood pressure control in the Sub Saharan Africa; a physician's perspective. Post Grad Doct 2004; 25:4

61. Okonta JM, Nduka V, Idodo VE. Prescribing pattern of antihypertensives and antidiabetic agents in a secondary healthcare institution in Nigeria. J Pharm Sci Res 2012; 5:2 - 17.

62. Ukwe CV, Ubaka CM. Antihypertensive drug prescribing in a tertiary hospital in eastern Nigeria. Trop J Pharm Res 2012; 11:297 305

63. Ojji DB, Ajayi SO, Mamven MH, Alfa J, Albertino D. Pattern of prescription of antihypertensives medications in a tertiary healthcare facility in Abuja, Nigeria. Ethn Dis 2013; 23:480 - 483.

64. Babawale TB, Cashmir EA, Christiana OA, Amam CM. Hypertension prescription pattern of non-specialist general practitioners in Lagos, Nigeria. Niger J Gen Pract 2016; 14 6- 10.

65. Jhaj R, Goel NK, Gautam CS. Prescribing pattern and cost of antihypertensive drugs in an internal medicine clinic. Indian Heart $\mathrm{J}$ 2001; 53: $523-527$

66. Whitworth JA, Chartmers J. World Health Organization/ international society of hypertension [WHO/ISH] hypertension guidelines. ClinExpHypertens 2004; 26:247 - 252.

67. Khurshid F, Aqil M, Alam MS, Kapour P, Pillai KK. Antihypertensive medication prescribing pattern in a University teaching Hospital in South Delhi. IJPSR 2012; 3(7):2057 - 2063.

68. Liu PH, Wang ID. Antihypertensive medication prescription pattern and time trends for newly diagnosed uncomplicated hypertension patients in Taiwan. BMC Health Serv Res 2008; 133.

69. Obikeze OO, Ige OK, Osungbade KO, Olumide EA, Asuzu MC. An overview of the national health insurance scheme in Nigeria. Dokita 2010; $1: 15-21$.

70. Salako BM, Ayodele OE, Kadiri S, Arije A. Assessment of blood pressure in a black African population. Cardio Trop 2002; 9: $3-6$

71. Attaei MW, Khatib R, Mckee M, Lear S, Dagenois G, Igumbor EU, AlHabib KF, Kaur M et al. Availability and affordability of blood pressure lowering medicines and the effect on blood pressure in high income, middle income and low income countries: an analysis of PURE data. Lancet Public Health 2017; 2: e411 - 19.

72. Cameron A, Ewem M, Ross-Dagnan D, Ball D, Laing R. Medicine prices, availability and affordability in 36 developing and middle income countries: a secondary analysis. Lancet 2009; 373: $240-249$.

73. Lim SS, Gaziano TA, Gakidou E et al. Prevention of cardiovascular diseases in high risk individuals in low income and middle income countries, health effects and costs. Lancet. 2007; 370: 2054 - 2062. 